Meta

Journal des traducteurs

Translators' Journal

\title{
La stylistique comparée du français et de l'anglais
}

\section{Jean Darbelnet}

Volume 28, numéro 4, décembre 1983

URI : https://id.erudit.org/iderudit/002463ar

DOI : https://doi.org/10.7202/002463ar

Aller au sommaire du numéro

Éditeur(s)

Les Presses de l'Université de Montréal

ISSN

0026-0452 (imprimé)

1492-1421 (numérique)

Découvrir la revue

Citer cette note

Darbelnet, J. (1983). La stylistique comparée du français et de l'anglais. Meta, 28(4), 417-417. https://doi.org/10.7202/002463ar d'utilisation que vous pouvez consulter en ligne.

https://apropos.erudit.org/fr/usagers/politique-dutilisation/ 


\section{BLOC-NOTES}

\section{LA STYLISTIQUE COMPARÉE DU FRANÇAIS ET DE L'ANGLAIS}

Marquant cette année son $25^{\mathrm{e}}$ anniversaire, la Stylistique comparée du français et de l'anglais, de J.-P. Vinay et de J. Darbelnet, poursuit une carrière honorable auprès des usagers des deux langues, qu'ils soient francophones ou anglophones, traducteurs ou spécialistes de seconde langue.

Auprès des linguistes, elle trouve un accueil plus réservé parce que ceux-ci tendent à la juger comme une théorie de la traduction, alors que ses auteurs ne l'ont jamais conçue comme telle. Tout au plus vise-t-elle à dégager certains principes. Et c'est l'éditeur qui a eu l'idée du sous-titre "Méthode de traduction" qu'elle n'est que dans une certaine mesure.

Essentiellement, la SCFA est un répertoire des différences caractéristiques entre les deux langues dont elle traite. Àce titre, elle continue à rendre service à un public divers qui, quels que soient ses objectifs particuliers, cherche à bien posséder les deux langues en évitant leurs interférences réciproques. Il n'est pas exagéré de dire que sa réputation ne se limite pas aux seuls pays de langues anglaise et française.

JEAN Darbelnet 